\title{
Frequency Distribution of Fluoroquinolones-Resistant Enterococcus faecalis Isolates from Patients with Prostatitis in Golestan Province, Iran
}

\author{
Hamideh Askari (MSc) \\ Department of Biology, Gorgan \\ Branch, Islamic Azad University, \\ Gorgan, Iran \\ Leila Fozouni (PhD) \\ Department of Biology, Gorgan \\ Branch, Islamic Azad University, \\ Gorgan, Iran \\ Hamid Reza Pordeli (PhD) \\ Department of Biology, Gorgan \\ Branch, Islamic Azad University, \\ Gorgan, Iran
}

Corresponding author: Leila Fozouni (PhD)

Email: lili_kia@yahoo.com

Tel: +98-9111518674

Address: Department of Biology,

Gorgan Branch, Islamic Azad

University, Gorgan, Iran

Received: 06 Aug 2018

Revised: 01 Nov 2018

Accepted: 05 Nov 2018

\section{c) (i) (8)}

This work is licensed under a Creative Commons Attribution 4.0 License.
ABSTRACT

Background and 0bjectives: Enterococcus faecalis is a major cause of bacterial prostatitis, which can increase the risk of developing prostate cancer if mistreated or left untreated. The aim of this study was to evaluate resistance of $E$. faecalis strains isolated from patients with prostatitis to three fluoroquinolones.

Methods: In this cross-sectional study, we collected urine specimen from 164 patients hospitalized in six hospitals in the Golestan Province, Iran. Biochemical and bacteriological tests were carried out to identify E. faecalis strains. Pattern of resistance to ciprofloxacin, levofloxacin and norfloxacin was studied using the agar disk diffusion method (Kirby-Bauer method). The broth microdilution test was performed to determine minimum inhibitory concentrations (VIIS) of fluoroquinolones according to the CLSI M100-S25 (2015) criteria.

Results: 0f 164 isolates, 39 (23.0\%) were identified as E. faecalis. Frequency of resistance to ciprofloxacin, norfloxacin and levofloxacin was $12.0 \%, 12.0 \%$ and $2.6 \%$, respectively. The $\mathrm{MIC}_{90}$ of ciprofloxacin against the isolates was $4 \mu \mathrm{g} / \mathrm{ml}$, which was 4 -fold lower than that of norfloxacin $\left(\mathrm{MIC}_{90}=16 \mu \mathrm{g} / \mathrm{ml}\right)$ and 2-fold lower than that of levofloxacin $\left(\mathrm{IIIC} \mathrm{C}_{90}=0 \mu \mathrm{g} / \mathrm{ml}\right)$. We found no significant difference between the isolates in terms of resistant to the fluoroquinolones $(\mathrm{P}>0.01)$.

Conclusion: 0ur results show that E. faecalis is one of the most common causes of bacterial prostatitis, and fluoroquinolones are still effective for treating the infection despite the reports of fluoroquinolones resistance in Iran. Moreover, levofloxacin may be a more suitable and effective antibiotic than ciprofloxacin and norfloxacin for treatment of this infection.

Keywords: Enterococcus faecalis, Prostatitis, Drug Resistance, Iran. 


\section{INTRODUCTION}

Enterococci are important causes of nosocomial and community-acquired infections (1). Hospital-acquired infections prolong hospitalization period, which significantly increases health care costs (2). Enterococcus faecalis and Enterococcus faecium are the most common Enterococci that cause human infections, such as urinary tract infections (UTIs), ulcers and endocarditis (3, 4). E. faecalis is an anaerobic, gram-positive and catalase-negative bacterium that can ferment glucose without gas production. The bacterium often resides in the urinary tract and is regarded as the second most common nosocomial pathogen (5). The intrinsic resistance of Enterococci to antibiotics and their ability to acquire resistance contribute to the survival of these organisms in hospital settings (6).

Bacterial prostatitis (BP) is caused by localization of UTI-causing bacteria (e.g. E. faecalis) (7). According to the World Health Organization, the increased prevalence of drug-resistant pathogens is an important global health problem. Fluoroquinolones such as ciprofloxacin and norfloxacin have been effectively used for the treatment of various bacterial infections including BP. Levofloxacin is a new-generation fluoroquinolone that is widely applied for treatment of infections caused by grampositive, gram-negative, aerobic and anaerobic microorganisms. All three antibacterial agents are recommended as first-line treatments for BP (8). In this study, we investigate frequency of resistance to fluoroquinolones among $E$. faecalis isolates from patients with BP.

\section{MATERIALS AND METHODS}

In this cross-sectional study, urine specimens were taken from 164 patients (average age: $57 \pm 9$ years) with symptoms of prostatitis who were admitted to six hospitals in the Golestan Province, north of Iran, from September 2015 to October 2017. The symptoms included perineal pain, pelvic pain, testicular pain and bladder symptoms such as dysuria and frequent or urgent urination. Before sampling, we made sure that patients had not taken any antibiotics. About 5-10 ml of midstream specimens of urine was collected. The specimens were cultured on blood agar (Merck, Germany) for colony counting, and were then cultured in sodium azide broth and sodium azide agar (Sigma Aldrich, USA). After incubation, the bacteria were subjected to gram staining and catalase test. Gram-positive, catalase-negative Enterococci were further studied using standard biochemical tests including LPyrrolidonyl-beta-naphthylamide hydrolysis test, culture in tryptic soy broth (TSB) containing $6.5 \%$ salt, and Esculin hydrolysis test in the presence of bile and telluride $0.04 \%$. Antibiotic susceptibility testing was performed by the agar disk diffusion (Kirby-Bauer) method using ciprofloxacin $(5 \mu \mathrm{g})$, norfloxacin $(10 \mu \mathrm{g})$ and levofloxacin $(5 \mu \mathrm{g})$ disks purchased from Mast Co., UK. In this test, a bacterial suspension equal to $0.5 \mathrm{McFarland}$ standard was prepared and cultured in MüllerHinton agar (Merck, Germany). After placing the antibiotic disks, plates were incubated for $16-18 \mathrm{~h}$ at $37^{\circ} \mathrm{C}$. Diameter of inhibition zone around the disks was measured and recorded in millimeters. The results were interpreted as resistant, susceptible and intermediate based on the CLSI M100-S25 (2015) criteria (9).

In order to determine minimum inhibitory concentration (MIC) of the antibiotics, all resistant strains were further investigated using the broth microdilution test. Stock solutions of ciprofloxacin (Sigma Aldrich, USA) in water and norfloxacin and levofloxacin (Sigma Aldrich, USA) in water with $0.1 \mathrm{~mol} / \mathrm{L} \mathrm{NaOH}$ were prepared. Next, serial dilutions were made and added to a 96-well microplate containing Müller-Hinton broth (Merck, Germany). Bacterial suspensions with turbidity of 0.5 McFarland standard were inoculated in the wells. The plate was incubated at $37{ }^{\circ} \mathrm{C}$ for 16 to $20 \mathrm{~h}$. Wells containing the drug and broth were considered as the negative control, while those containing the broth and bacterial suspension were considered as the positive control. Minimum concentration of the antibiotic that inhibited growth of $90 \%$ of isolates was regarded as the $\mathrm{MIC}_{90}$. The plates were placed in an ELISA reader to confirm results of the optical turbidity measurement. According to the CLSI-M100-S25 standard (9), the strains with MIC $\leq 1 \mu \mathrm{g} / \mathrm{ml}$ were identified as susceptible, the ones with $\mathrm{MIC}=2 \mu \mathrm{g} / \mathrm{ml}$ as intermediate, and the ones with $\mathrm{MIC} \geq 4 \mu \mathrm{g} / \mathrm{ml}$ were identified as resistant to ciprofloxacin; the strains with $\mathrm{MIC} \leq 2 \mu \mathrm{g} / \mathrm{ml}$ were identified as susceptible, the ones with $\mathrm{MIC}=4 \mu \mathrm{g} / \mathrm{ml}$ as 
intermediate, and the ones with $\mathrm{MIC} \geq 8 \mu \mathrm{g} / \mathrm{ml}$ were identified as resistant to levofloxacin; the strains with $\mathrm{MIC} \leq 4 \mu \mathrm{g} / \mathrm{ml}$ were identified as susceptible the ones with $\mathrm{MIC}=8 \mu \mathrm{g} / \mathrm{ml}$ as intermediate, and the ones with $\mathrm{MIC} \geq 16 \mu \mathrm{g} / \mathrm{ml}$ were regarded as resistant to norfloxacin (9). To determine the minimum bactericidal concentration (MBC), $100 \mu \mathrm{l}$ of the wells' content with a concentration higher than the MIC value and $100 \mu \mathrm{l}$ of the positive control were separately transferred onto MüllerHinton agar and incubated at $37{ }^{\circ} \mathrm{C}$ for 24 h. E. faecalis ATCC29212 was used as the control strain. Data were analyzed using the chisquare test and one-way ANOVA in SPSS software (version 18). A p-value of less than 0.01 was considered as statistically significant.

\section{RESULTS}

Of 164 isolates from patients with symptoms of prostatitis, $39(23.8 \%)$ were identified as E. faecalis. According to the results of the disk diffusion method, frequency of resistance to ciprofloxacin, norfloxacin and levofloxacin was $12.8 \%, 12.8 \%$ and $2.6 \%$, respectively (Figure 1).

Figure 1- Frequency distribution of drug resistance among $\boldsymbol{E}$. faecalis isolates. R: resistant; I: intermediate; S: susceptible.

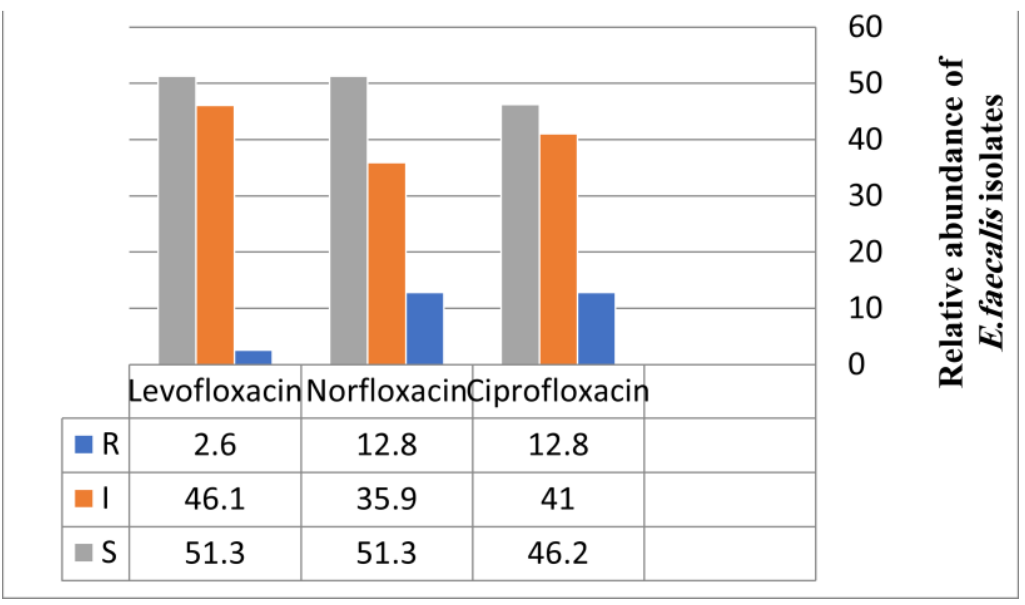

The $\mathrm{MIC}_{90}$ of ciprofloxacin against the isolates was $4 \mu \mathrm{g} / \mathrm{ml}$, which was 4 -fold lower than that of norfloxacin $\left(\mathrm{MIC}_{90}=16 \mu \mathrm{g} / \mathrm{ml}\right)$ and 2-fold 1 ower than that of levofloxacin $\left(\mathrm{MIC}_{90}=8 \mu \mathrm{g} / \mathrm{ml}\right)$. Concentration of $8 \mu \mathrm{g} / \mathrm{ml}$ inhibited the growth of all isolates except Those resistant to norfloxacin $(32 \mu \mathrm{g} / \mathrm{ml})$ and levofloxacin $(16 \mu \mathrm{g} / \mathrm{ml})$ (Table 1$)$. As shown in table 2, E. faecalis isolates did not differ significantly in terms of resistance to the fluoroquinolones.

Table 1- MIC and MBC values of fluoroquinolones against $\boldsymbol{E}$. faecalis isolates

\begin{tabular}{lccccc}
\hline Strains & $\mathrm{MIC}_{50}(\mu \mathrm{g} / \mathrm{ml})$ & $\begin{array}{c}\mathrm{MIC}_{90} \\
(\mu \mathrm{g} / \mathrm{ml})\end{array}$ & $\mathrm{MBC}(\mu \mathrm{g} / \mathrm{ml})$ & $\begin{array}{c}\text { Concentrations } \\
\text { range }(\mu \mathrm{g} / \mathrm{ml})\end{array}$ & Antibiotics \\
\hline E. faecalis & 2 & 4 & 8 & $\mathbf{1 6 - 0 . 0 3}$ & Ciprofloxacin \\
E. faecalis & 4 & 16 & 32 & $\mathbf{6 4 - 0 . 1 2 5}$ & Norfloxacin \\
E. faecalis & 4 & 8 & 16 & $\mathbf{3 2 - 0 . 0 6}$ & Levofloxacin \\
\hline
\end{tabular}

Table 2- Comparison of growth of $\boldsymbol{E}$. faecalis strains under eaual concentrations of fluoroauinolones

\begin{tabular}{|c|c|c|c|c|c|c|}
\hline \multirow{2}{*}{$\begin{array}{l}\text { Concentration } \\
(8 \mu \mathrm{g} / \mathrm{ml})\end{array}$} & \multirow{2}{*}{$\begin{array}{c}\text { Strains } \\
\left(1.5 \times 10^{8} \mathrm{cfu} / \mathrm{ml}\right)\end{array}$} & \multicolumn{2}{|c|}{ No Growth } & \multicolumn{2}{|c|}{ Growth } & \multirow[t]{2}{*}{ Comparison } \\
\hline & & Number & Percent & Number & Percent & \\
\hline Ciprofloxacin & E. faecalis & 39 & 100 & $\mathbf{0}$ & $\mathbf{0}$ & $\begin{array}{c}X^{2}=0 \\
\text { NS }\end{array}$ \\
\hline Norfloxacin & E. faecalis & 35 & 89.7 & 4 & 10.3 & $\begin{array}{c}X^{2}=0 \\
\text { NS }\end{array}$ \\
\hline Levofloxacin & E. faecalis & 36 & 92.3 & 3 & 7.7 & $\begin{array}{c}X^{2}=0 \\
\text { NS }\end{array}$ \\
\hline
\end{tabular}

NS: No significant difference in terms of drug resistance based on one-way ANOVA 


\section{DISCUSSION}

E. faecalis is a gram-positive, commensal bacterium in the gastrointestinal tract of humans that can cause UTI and BP in hospitalized patients (7). Nosocomial infections caused by E. faecalis and regular use of antibiotics for preventing recurrence have resulted in the emergence of resistant strains, which complicates the treatment process (10). A 4 to 12 weeks treatment with fluoroquinolones including ciprofloxacin, levofloxacin and norfloxacin has been recommended for eradication of bacteria and treatment of $\mathrm{BP}(11,12)$.

In present study, the frequency of E. faecalis strains was $23.8 \%$ in patients with symptoms of BP. In a previous study in Iran, of 339 Enterococcus strains isolated from patients in the Labbafinejad and Shahid Chamran hospitals, $273(77.5 \%)$ were identified as $E$. faecalis (13). In Hamedan (Iran), the frequency of E. faecalis was $62.5 \%$ (14). In another survey, $92.3 \%$ of Enterococcus strains were identified as E. faecalis (15). Researchers detected E. faecalis in $79 \%$ of the samples taken from patients, of which 29\% were ciprofloxacin resistant (16). The disparity between the results could be attributed to geographical factors and difference in health standards and conditions of the patients. In the present study, of 39 E. faecalis isolates, $12.8 \%$ showed resistance to ciprofloxacin, which is higher than the rates observed in previous studied $(7,13)$. Norfloxacin and levofloxacin are effective for treatment of BP caused by $E$. faecalis, Escherichia coli and Proteus mirabilis $(12,17,18)$.

In a study in western Iran, the frequency of resistance to ciprofloxacin and levofloxacin was reported to be $68 \%$ in gram-negative isolates (19), which is higher than the rate observed in our study. Moreover, the frequency of resistance of gram-negative isolates to these two antibiotics in Canada and
Syria was $79 \%$ and $68 \%$, respectively $(20,21)$. This disparity between the findings could be related to the difference in bacteria strains, sources of antibiotic resistance and geographical factors.

In this study, the frequency of ciprofloxacinand norfloxacin-resistant E. faecalis isolates was identical and similar to results of Yumi and Gilho (7).

In our study, $56.4 \%$ of the strains were susceptible to levofloxacin, and only one strain (2.6\%) was levofloxacin resistant. This finding suggests that levofloxacin may be a more effective agent for treatment of BP caused by E. faecalis.

\section{CONCLUSION}

Our results reveal that E. faecalis is one of the most common causes of BP, and fluoroquinolones are still effective for treating the infection despite the reports of fluoroquinolones resistance in Iran. Results of the antibiotic susceptibility testing indicate that levofloxacin may be a more suitable and effective antibiotic than ciprofloxacin and norfloxacin for treatment of BP.

It is recommended to conduct annual screening programs for men, especially those over the age of 50 years and with symptoms of prostatitis, to help reduce prevalence of BP and UTI.

\section{ACKNOWLEDGMENTS}

This study has been supported by the Research Council of the Islamic Azad University of Gorgan, Iran. We wish to thank the staff of hospitals in the Golestan Province for cooperating in the study.

\section{CONFLICT OF INTEREST}

The authors declare that there is no conflict of interest regarding publication of this study. 


\section{REFERENCES}

1. Goossens H, Jabes D, Rossi R, Lammens C, Privitera $\mathrm{G}$, Courvalin $\mathrm{P}$. European survey of vancomycinresistant enterococci in at-risk hospital wards and in vitro susceptibility testing of ramoplanin against these isolates. J Antimicrob Chemother. 2003; 51(3): 5-12.

2. Askarian M, Gooran NR. National nosocomial infection surveillance system-based study in iran: Additional hospital stay attributable to nosocomial infections. Am J Infect control .2003; 31(8): 465-8.

3. Maria DA, Citron DM, K wok R. Evaluation of the velogene genomic assay for detection of vanA and vanB gene in vancomycin resistant Enterococcus Species. J Clin Microbial. 2004; 42(4): 1751-52. doi: 10.1128/JCM.42.4.1751-1752.2004.

4. Murray BE. Vancomycin resistant Enterococcal infections. New Eng J Med. 2000; 342(10): 710-21.

5. Jawetz E, et al. Medical microbiology. $26^{\text {th }}$ ed. New York; Toronto; MCGraw Hill Medical. 2013; 209-40.

6. Walker TS. Microbiology. philadelphia. W.B. 2003; Saunders Company.

7. Yumi Seo, Gilho Lee. Antimicrobiol Resistance Pattern in Enterococcus Faecalis Strains Isolated From Expressed Prostatic Secretions of Patients with chronic Bacterial Prostatitis. Korean J Urol. 2013; 54(7): 47781.

8. Dennis Kasper, Anthony Fauci, Stephen Hauser. Harrisons Principles Of Internal Medicine. $19^{\text {th }}$ ed. 2015; 340-43.

9. Clinical and Laboratory Standards Institute: Performance standards for antimicrobial 324 susceptibility testing; Twenty-Fifth Informational Supplement M100-S25. 325. 2015:Clinical and Laboratory Standards Institute. Wayne, PA.

10. Lee G .Ciprofloxacin Resistance in Enterococcus faecalis Strains Isolated From Male Patients With Complicated Urinary Tract Infection. Korean J Urol. 2013; 54(6): 388-93. doi: 10.4111/kju.2013.54.6.388.

11. Dan M, Golomb J, Gorea A, Braf Z, Berger SA. Concentration of ciprofloxacin in human prostatic tissue after oral administration. Antimicrob Agents Chemother. 1986; 30(1): 88-89.

12. Jang WH, Yoo DH, Park SW. Prevalence of and risk factors for levofloxacin-resistant E. coli isolated from outpatients with urinary tract infection. Korean $\mathrm{J}$ Urol. 2011; 52(8): 554-9.
13. FeizAbadi, M.,Asadi S . Study of Antibiotic Resistance Pattern of Enterococcus faecalis and Enterococcus faecium Strains in Labafinezhad and Shahidchamran Hospitals.Pajoohandeh J. 2004; 6:33339.

14. Najafi Mosleh M, Nasaj M, Rahimi F, Arabestani MR. Distribution Rates and Antibiotic Resistance Pattern of Enterococcus Spp. Isolated from Clinical Specimens of Hospitals in Hamedan. J Mazandaran Univ Med Sci. 2014; 24(117): 92-102.

15. Firoozeh F, Akha M, Oskoii, Antibiotic M. Resistance in Enterococcus Strains Isolated from Clinical Specimens.Tabriz University J .2010;1:61-7.

16. Hällgren A, Abednazari H, Ekdahl C, Hanberger H, Nilsson M, Samuelsson A, et al. Antimicrobial susceptibility patterns of Enterococci in intensive care units in Sweden evaluated by different MIC breakpoint systems. Journal of Antimicrobial Chemotherapy. 2001; 48(1): 53-62.

17. Naber KG, Busch W, Focht J. Ciprofloxacin in the treatment of chronic bacterial prostatitis: a prospective, non-comparative multicentre clinical trial with long-term follow-up. The German Prostatitis Study Group. Int J Antimicrob Agents. 2000; 14(2): 143-9.

18. Panagopoulos P, Antoniadou A, Kanellakopoulou K, Tsiodras S, Katsarolis I, Papadopoulos A, et al. Fluoroquinolone treatment of chronic bacterial prostatitis: a prospective cohort study. J Chemother. 2009; 21(3): 317-21.

19. Lorestani R, Akya A, Elahi A. The Mutations of Topoisomerase Genes and Their Effect on Resistance to Fluoroquinolones in Extended-Spectrum $\beta$-LactamaseProducing Escherichia coli. Jundishapur J Nat Pharm Prod. 2018; 13(1): 1-6.

20. Lagace-Wiens PR, Nichol KA, Nicolle LE, Decorby MR, McCracken M, Alfa MJ, et al. ESBL genotypes in fluoroquinolone-resistant and fluoroquinolonesusceptible ESBL-producing Escherichia coli urinary isolates in Manitoba.Can J Infect Dis Med Microbiol. 2007; 18(2): 133-7.

21. Alheib O, Al Kayali R, Abajy MY. Prevalence of plasmid-mediated quinolone resistance (PMQR) determinants among extended spectrum beta-lactamases (ESBL)-producing isolates of escherichia coli and klebsiella pneumoniae in Aleppo, Syria. Arch Clin Infect Dis. 2015;10(3): e20631. 